\title{
Internet Filtering and Adolescent Exposure to Online Sexual Material
}

\author{
Andrew K. Przybylski, $\mathrm{PhD}^{1,2}$ and Victoria Nash, $\mathrm{PhD}^{1}$
}

\begin{abstract}
Early adolescents are spending an increasing amount of time online, and a significant share of caregivers now use Internet filtering tools to shield this population from online sexual material. Despite wide use, the efficacy of filters is poorly understood. In this article, we present two studies: one exploratory analysis of secondary data collected in the European Union $(n=13,176)$, and one preregistered study focused on British adolescents and caregivers $(n=1,004)$ to rigorously evaluate their utility. In both studies, caregivers were asked about their use of Internet filtering, and adolescent participants were interviewed about their recent online experiences. Analyses focused on the absolute and relative risks of young people encountering online sexual material and the effectiveness of Internet filters. Results suggested that caregiver's use of Internet filtering had inconsistent and practically insignificant links with young people reports of encountering online sexual material. Our findings underscore the need for randomized controlled trials to determine the extent to which Internet filtering and related technologies support versus thwarts young people online, and if their perceived utility justifies their financial and informational costs.
\end{abstract}

Keywords: adolescents, Internet, Internet filtering, online sexual material

\section{Introduction}

I NTERNET USE, particularly mobile Internet use, has become increasingly significant in children's lives, with average weekly time online doubling for United Kingdom 12-15 year olds between 2005 and 2015. ${ }^{1}$ For all the opportunities that the Internet provides for education and communication, concerns about children's access to illegal or potentially harmful content such as pornography remain high on policy agendas, despite the challenges of assessing exposure levels. $^{2,3}$ While exposure and prevalence studies vary in their methods, definitions, and timescales, reviews of the research suggest that many minors report having seen pornography online, with figures higher among boys and for those in older age groups (14-16 years). ${ }^{3-5}$ Boys are also more likely to report intentional viewing of pornography. Few studies measure the frequency of exposure or access to pornography, but a recent large-scale survey of school children across five European countries reported that between 19 percent and 30 percent of 14-17 year olds claim to watch online pornography regularly. ${ }^{6}$ In addition to consuming sexual content, adolescents are exchanging, and even creat- ing it using their smartphones and other mobile devices. Prevalence figures for sexting are well studied though also vary widely, ${ }^{7}$ raising additional policy concerns relating to coercion, consent, and illegal image creation. ${ }^{8}$

Given the dramatic shifts in Internet usage and the widespread availability of online sexual material, Internet filterstechnologies designed to prevent access to pornography or other online content perceived as harmful—are presented as possible protective measures, and on average, a quarter of European families report using them. ${ }^{4,9}$ The United Kingdom government has demonstrated its strong support for such technical protection measures, by requiring Internet Service Providers (ISPs) to provide opt-out family-friendly Internet filtering at household level. ${ }^{10}$ This level of intervention is unusual in Europe, as although several governments do mandate the use of filters by ISPs, this usually only extends to the removal of child abuse materials or other locally illegal content. ${ }^{11,12}$ However, following the signature of a European Framework agreement supporting safer Internet use by children and teenagers in 2008, many European states require their mobile operators to follow codes of conduct that should limit minors' access to pornography. ${ }^{13}$

\footnotetext{
${ }^{1}$ Oxford Internet Institute, University of Oxford, Oxford, United Kingdom.

${ }^{2}$ Department of Experimental Psychology, University of Oxford, United Kingdom.
}

(c) Andrew K. Przybylski and Victoria Nash 2018; Published by Mary Ann Liebert, Inc. This Open Access article is distributed under the terms of the Creative Commons Attribution Noncommercial License (http://creativecommons.org/licenses/by-nc/4.0/) which permits any noncommercial use, distribution, and reproduction in any medium, provided the original author(s) and the source are cited. 
Despite their wide adoption in the developed world, filters are expensive and imperfect technologies in three key ways: First, in financial terms, they are costly to develop and maintain, ${ }^{14}$ and even if offered free at the point of use, their costs are ultimate borne by the consumer or taxpayer. ${ }^{15}$ Second, in practical terms, they present the problem of underblocking, a phenomenon in which new problematic sites, content, and apps may slip through. Finally, in informational terms, filters also present the problem of overblocking, wherein the content is unnecessarily blocked, restricting access to necessary health, cultural, and social information. In practice, this means that filters offer only imperfect protection, and impose informational costs on children and adolescents seeking legitimate information, contrary to the information rights recognized in the United Nations Convention on the Rights of the Child. ${ }^{16}$ Overblocking weighs most heavily on those who lack accessible sources of information offline; research suggests that lesbian, gay, bisexual, transgender, and questioning adolescents, for example, are particularly reliant on the Internet for information about health and relationships. ${ }^{17,18}$

Given these substantial costs and limitations, it is noteworthy that there is little consistent evidence that filtering is effective at shielding young people from online sexual material. A pair of studies reporting on data collected in 2005, before the rise of smartphones and tablets, provides tentative evidence that Internet filtering might reduce the relative risk of young people countering sexual material. ${ }^{19,20}$ A more recent study, analyzing data collected a decade after these papers, provided strong evidence that caregivers' use of Internet filtering technologies did not reduce children's exposure to a range of aversive online experiences including, but not limited to, encountering sexual content that made them feel uncomfortable. ${ }^{21}$ Given studies on this topic are few in number and the findings are decidedly mixed, the evidence base supporting the widespread use of Internet filtering is currently weak.

\section{Present research}

The present studies were conducted to address this gap in our knowledge by directly assessing the extent to which caregivers' use of Internet filtering technology prevents adolescents from encountering online sexual material. Our aim was to combine secondary data analysis with a preregistered hypothesis testing approach to rigorously assess the question: Do filters have a statistically significant protective effect and if so, is this protective effect practically significant?

Given the very large representative sample of caregivers and adolescents analyzed, and the fact that Internet filters are designed explicitly to filter sexual online content we hypothesized that caregiver use of Internet filtering would have a statistically significant protective effect. However, in light of the mixed findings in the literature we were not confident that this effect would be practically significant. To determine such effectiveness, we applied a statistical technique developed for epidemiological research, namely the number needed to treat (or NNT), which helps clinicians assess the benefits of a treatment relative to its costs or alternative interventions. Briefly, NNT is the number of patients who must be treated for one additional patient to receive a health benefit compared with those without treatment. ${ }^{22}$ A low NNT, between 1 and 10 , is desirable as it minimizes the costs associated with treating many individuals to benefit just one. ${ }^{23,24}$ In the con- text of Internet filtering, number needed to filter (or NNF) can be calculated to indicate the number of households that must use filtering tools, for one additional child not to be exposed to online sexual content. With this in mind, we sought to determine if fewer than 10 households needed to have Internet filters in place for one additional child to be protected from exposure to a range of online sexual materials.

\section{Methods \\ Participants}

A representative subsample of 9,352 male and 9,357 female young people, ranging in age from 11 to 16 years $(M=13.5$, $S D=1.7$ ) was drawn from data collected by the EU Kids Online II Study ${ }^{25}$ for Study 1. EU Kids Online II, a large-scale primary survey of children and parents, was conducted to measure online risks, opportunities, and experiences of young people on the Internet. An equal number of caregivers provided data, so that there were a total of 18,709 caregiver-children pairs. Data were collected in person and explanatory variable detailed below was collected through an interview, whereas the outcome variable was assessed with a pen-and-paper questionnaire administered during the visit. Participants were recruited from the European Union (EU) nations, Austria, Belgium, Bulgaria, Cyprus, Czech Republic, Germany, Denmark, Estonia, Greece, Spain, Finland, France, Hungary, Ireland, Italy, Lithuania, The Netherlands, Norway, Poland, Portugal, Romania, Sweden, Slovenia, the United Kingdom, and a non-EU country, Turkey. For Study 2, a sample of 1,004 adolescents (aged 14 and 15) and an equal number of their caregivers living in England, Scotland, and Wales was recruited using geographic data, household socioeconomic class, participant age, and gender factors based on 2011 United Kingdom Census data. In line with the best open science practices, all study materials, data, and codes are freely available on the Open Science Framework (OSF). ${ }^{26}$

\section{Ethical review}

A comprehensive ethical review for the data collection was conducted by the London School of Economics Ethics Committee (Study 1) and at the University of Oxford (Study 2).

\section{Measures}

Explanatory variable: use of Internet filters. In Study 1, this measure was recorded in face-to-face interviews with parents who were asked if they (or their partners or cocaregivers) made use of "Parental controls or other means of blocking or filtering some types of website." In Study 2, caregivers completed a self-report survey item that asked "Do you use the content filters provided by your broadband Internet service and/ or mobile providers for the computers, smartphones, or other devices that your child uses?" In both cases, caregivers were provided with three response options 0 "Don't know," 1 "No," and 2 "Yes." Table 1 presents the descriptive statistics for caregiver responses, and indicates that filters were much more frequently used in the 2018 U.K. data (Study 2; 48.8 percent) compared with the 2010 E.U. data (23.0 percent).

Outcome variable: exposure to online sexual material. This variable was assessed by asking young people to complete a confidential pen-and-paper questionnaire (Study 1) or a selfreport survey (Study 2) regarding their online experiences in 
Table 1. Observed Frequencies of Caregiver Use of Internet Filtering

\begin{tabular}{|c|c|c|c|c|c|c|c|c|c|}
\hline & \multirow{2}{*}{$\begin{array}{c}\text { Overall } \\
\text { Total }\end{array}$} & \multicolumn{2}{|c|}{ Gender } & \multicolumn{6}{|c|}{ Age (years) } \\
\hline & & Boys & Girls & 11 & 12 & 13 & 14 & 15 & 16 \\
\hline \multicolumn{10}{|l|}{ Study 1 (EU, 2010) } \\
\hline No, percent & 73.2 & 72.5 & 73.8 & 67.8 & 67.4 & 70.5 & 73.5 & 78.1 & 81.6 \\
\hline Yes, percent & 23.0 & 23.4 & 22.5 & 28.7 & 28.5 & 25.1 & 22.8 & 18.3 & 14.7 \\
\hline Do not know, percent & 3.8 & 4.1 & 3.6 & 3.4 & 4.1 & 4.5 & 3.7 & 3.6 & 3.7 \\
\hline \multicolumn{10}{|l|}{ Study 2 (UK, 2018) } \\
\hline No, percent & 45.9 & 43.3 & 48.8 & - & - & - & 44.1 & 47.7 & - \\
\hline Yes, percent & 48.8 & 51.7 & 45.6 & - & - & - & 49.9 & 47.7 & - \\
\hline Do not know, percent & 5.3 & 5.0 & 5.6 & - & - & - & 6.0 & 4.5 & - \\
\hline
\end{tabular}

the past year (Study 1) or 6 months (Study 2). To ensure confidentiality and minimize socially desirable responding, respondents sealed their questionnaires into envelopes upon completion (Study 1), and caregivers were asked to not be present in the room when adolescents completed their surveys (Study 2). In both studies, participants were asked whether they had seen any of four possible forms of online sexual material in the past year. These included nudity "Images or video of someone naked," intimate body parts "Images or video of someone's 'private parts'," sexual behavior "Images or video of people having sex," and violent pornography "Images or video of movies that show sex in a violent way." It should be noted that these child-friendly descriptors may also capture exposure to nonpornographic materials, such as legally permissible health information, or 18-rated sexually explicit films or music videos. Table 2 presents the frequencies of each kind of sexual material encountered, and includes a composite measure that reflects whether any of the four forms of online sexual material was encountered.

\section{Results}

\section{Preliminary analyses}

Valid data from a total of 13,176 (Study 1) and 1,004 (Study 2) caregiver-child dyads were analyzed. Results indicated that exposure to online sexual material varied as a function of type of content, participant age, and gender (Table 2). Seeing images or video with nudity was most frequently reported (13.7 percent in Study 1; 33.2 percent in Study 2), whereas exposure to images or videos that show sex in a violent way was the least common (2.9 percent in Study 1; 9.9 percent in Study 2). Boys reported watching more of all forms of sexual content (between 1.7 percent and 6.9 percent higher), and reports of encountering online sexual material increased monotonically with age from a low of 7.5 percent (among 11 year olds) to a high of 35.4 percent (16 year olds) in Study 1, and were higher among the 15 year olds ( 40.6 percent) than among 14 year olds (35.4 percent) in Study 2.

\section{Study 1: exploratory analyses}

Chi-square analyses presented in Table 3 indicated that caregiver use of Internet filtering was associated with a significantly lower likelihood that young people had recently encountered online sexual material. In standardized terms (i.e., Cramer's $\varphi$ ), the protective effects were quite modest for seeing nudity $\left(\varphi_{c}=0.067\right)$, private parts $\left(\varphi_{c}=0.053\right)$, people having sex $\left(\varphi_{c}=0.056\right)$, violent sex $\left(\varphi_{c}=0.031\right)$, or any kind of online sexual material $\left(\varphi_{c}=0.069\right)$ were very modest by this metric. ${ }^{27}$ Data were available for between 658 (France) and 806 (Bulgaria) participants from each country in the dataset, and country-level analyses were also conducted. The full results are available on the OSF, ${ }^{26}$ but we would caution against interpreting differences as they might be spurious because the large number of tests $(>100)$ does inflate the falsepositive findings' rate. The overall trend from these analyses indicates that there might be a small overall filtering effect across the EU nations and Turkey in aggregate.

TABLE 2.

\begin{tabular}{|c|c|c|c|c|c|c|c|c|c|}
\hline & \multirow{2}{*}{$\begin{array}{c}\text { Overall } \\
\text { Total }\end{array}$} & \multicolumn{2}{|c|}{ Gender } & \multicolumn{6}{|c|}{ Age (years) } \\
\hline & & Boys & Girls & 11 & 12 & 13 & 14 & 15 & 16 \\
\hline \multicolumn{10}{|l|}{ Study 1 (EU, 2010) } \\
\hline Images or video of so & 13.7 & 15.8 & 11.5 & 5.3 & 7.2 & 10.7 & 14.72 & 20.9 & \\
\hline ivate parts," percent & 9.3 & 11.2 & 7.3 & 3.0 & 3.7 & 6.7 & 10.3 & 8 & \\
\hline Images or & 10.1 & 13.6 & 6.7 & 3.1 & 4.6 & 6.9 & 11.2 & 16.2 & \\
\hline violent way, percent & 2.9 & 3.8 & 2.1 & 1.0 & 1.2 & 1.9 & 3.6 & 4.5 & \\
\hline Images or video of any of the above, perce & 20.5 & 24.4 & 23.4 & 7.5 & 10.8 & 15.8 & 23.43 & 32.6 & \\
\hline \multicolumn{10}{|l|}{ Study 2 (UK, 2018) } \\
\hline Images or video of & 33.2 & 35.7 & 30.2 & - & - & - & $30.6 ?$ & 35.7 & \\
\hline percent & 25.0 & 27.6 & 21.9 & - & - & - & 22.42 & 27.4 & \\
\hline Imag & 20.8 & 23.5 & 17.8 & - & - & - & 20.2 & 21.4 & \\
\hline violent way, percent & 9.9 & 11.3 & 8.4 & - & - & - & 8.1 & 11.6 & \\
\hline Images or video of any of the above, percent & 38.0 & 40.4 & 35.1 & - & - & - & 35.4 & 40.6 & \\
\hline
\end{tabular}




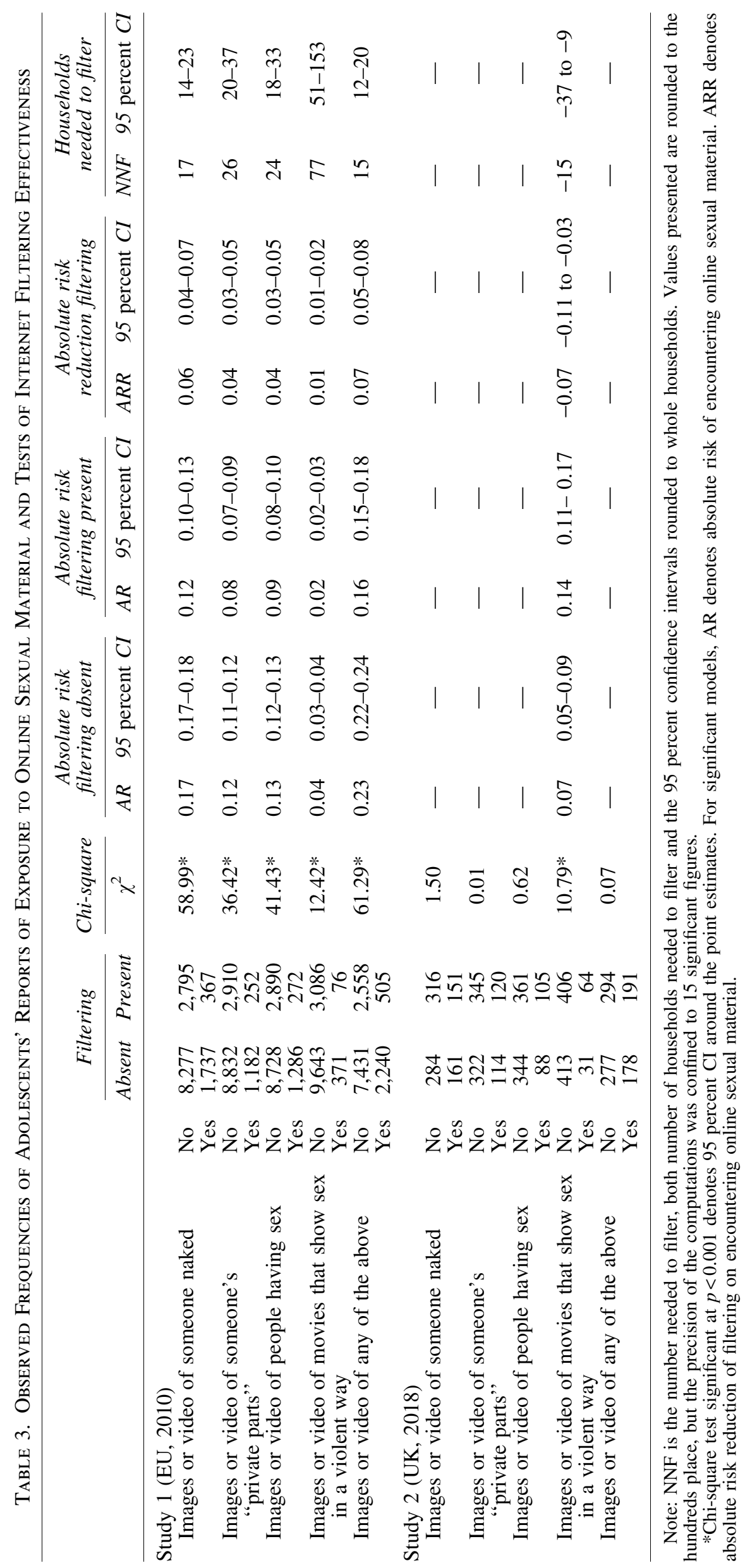


We calculated absolute risk reduction of exposure to online sexual material associated with caregivers using filtering technology in practical terms. ${ }^{28}$ These results, displayed in Table 3 (top), were used to calculate the number of households which would have to be filtered (NNF) to prevent one young person, who would otherwise see sexual material online, from encountering it over a 12 -month period. ${ }^{24}$ Depending on the form of content, results indicated that between 17 and 77 households would need to be filtered to prevent a young adolescent from encountering online sexual material. A protective effect lower than we would consider practically significant.

\section{Study 2: confirmatory analyses}

To provide a rigorous test of the exploratory findings dervied from the 2010 data we aimed to replicate the findings we derived from Study 1 with a follow-up study we ran with caregivers and adolescents in England, Wales, and Scotland. Given that the British ISP and mobile filtering systems now extend to phones and is on by default for new Internet subscribers, we reasoned that a NNF lower than 10 would be reasonable and practically impactful. In line with this goal, we registered an analysis plan ahead of data collection, ${ }^{29}$ and conducted an a priori power analysis to ensure that our planned sample size, $n=1,000$, would be highly sensitive $(1-\beta=0.95)$ using a two-tailed significance test.

Following the analytic approach implemented in Study 1, we did not find confirmatory evidence that filters were effective for seeing nudity, private parts, people having sex, or any of the four types in line with our preregistered hypotheses. In fact, contrary to our predictions we found evidence in the direction opposite to what we hypothesized in one case: households reporting using filters were more, not less, likely $\left(\varphi_{\mathrm{c}}=0.109\right)$ to have an adolescent who reported having seen violent pornography in the past 6 months (Table 3, bottom).

\section{Discussion}

\section{Summary}

Many caregivers and policy makers consider Internet filters a useful technology for keeping young people safe online. Although this position might make intuitive sense, there is little empirical evidence that Internet filters provide an effective means to limit children's and adolescents' exposure to online sexual material. There are nontrivial economic, informational, and human rights costs associated with filtering that need to be balanced against any observed benefits. Given this, it is critical to know possible benefits can be balanced against their costs. Our studies were conducted to test this proposition, and our findings indicated that filtering does not play a practically significant protective role.

Exploratory analyses using 2010 data from the EU indicated that adolescents whose parents used filtering reported statistically significantly lower levels of exposure to online sexual material. Although it was not surprising that these differences were statistically significant given the size of the sample, we did not expect the protective effect to be as small as observed. We found that this protective effect was modest, accounting for less than 0.5 percent of the variability we observed in our outcome variables. In other words, more than 99.5 percent of whether a young person encountered online sexual material had to do with factors beside their caregiver's use of Internet filtering technology. Our confirmatory ana- lyses, based on 2018 data from the United Kingdom, provided a more rigorous test of filtering effects. This delivered conclusive evidence that filters were not effective for protecting young people from online sexual material.

The findings speak to the mixed results in the existing literature and suggest that both positive and null effects observed for filtering might be partially accurate. Drawing on two large samples, we found only small and inconsistent effects. If filtering is not a robust or consistent factor in protecting young people online, it is possible that positive evidence are false-positive results driven by publication bias or the misinterpretation of statistically, but not practically, significant relationships in largescale social data. These findings suggest that future research testing the protective impact of filters should take the form of preregistered experimental trials that directly gauge the effectiveness of filtering across a range of youth outcomes.

From a policy perspective, these results suggest that if judged against the standards of a health treatment, on-bydefault home and mobile Internet filters are not an effective intervention to protect young people online. Our findings raise the question of whether mandatory state-funded Internet filtering in schools should still be regarded as a costeffective intervention, while also providing a clear rationale for investigation of other preventative methods, such as age verification tools, or educational strategies to support responsible behavior online and promote resilience.

\section{Limitations}

Our analysis presents limitations that point to two areas for improvement: First, although our data were broadly representative of European and British young people, the data in both cases were cross-sectional. Experimental evidence is needed to determine the value of implementing filters where none exist for young people at different ages and for families from diverse backgrounds. Second, although our study benefited from convergent reports between young people and their caregivers, the data were entirely for self-report. Future work should technologically verify the presence (or absence) of filtering technology as well as access to online sexual material.

\section{Conclusions}

The struggle to shape the experiences young people have online is now part of modern parenthood. This study was conducted to address the value of industry, policy, and professional advice concerning the appropriate role of Internet filtering in this struggle. Our preliminary findings suggested that filters might have small protective effects, but evidence derived from a more stringent and robust empirical approach ${ }^{30}$ indicated that they are entirely ineffective. These findings highlight the need for a critical cost-benefit analysis in light of the financial and informational costs associated with filtering and age verification technologies such as those now being developed in some European countries like the United Kingdom. ${ }^{31}$ Further, our results highlight the need for registered trials to rigorously evaluate the effectiveness of costly technological solutions for social and developmental goals.

\section{Author Contributions}

A.K.P. and V.N. are the sole authors of this work. A.K.P. designed the analytic approach, both interpreted the findings, and wrote the draft and final versions of the manuscript as submitted. 


\section{Author Disclosure Statement}

No competing financial interests exist.

\section{References}

1. Ofcom. (2016) Children's media literacy. http://stakeholders .ofcom.org.uk/market-data-research/media-literacy/childrens (accessed Mar. 7, 2016).

2. Livingstone S, Mason J. (2015) Sexual rights and sexual risks among youth online: a review of existing knowledge regarding children and young people's developing sexuality in relation to new media environments. http://eprints.lse.ac.uk/64567/1/ Livingstone_Review_on_Sexual_rights_and_sexual_risks_among online_youth_Author_2015.pdf (accessed Apr. 25, 2017).

3. Horvath MAH, Alys L, Massey K, et al. (2013) Basically... porn is everywhere: a rapid evidence assessment on the effects that access and exposure to pornography has on children and young people. https://core.ac.uk/display/17302511 (accessed May 6, 2016).

4. Mascheroni G, Cuman A. (2014) Net children go mobile: final report. http://netchildrengomobile.eu/ncgm/wp-content/ uploads/2013/07/NCGM_FinalReport_Country_DEF.pdf (accessed May 6, 2016).

5. Livingstone S, Smith PK. Annual research review: harms experienced by child users of online and mobile technologies: the nature, prevalence and management of sexual and aggressive risks in the digital age. Journal of Child Psychology and Psychiatry 2014; 55:635-654.

6. Stanley N, Barter C, Wood M, et al. Pornography, sexual coercion and abuse and sexting in young people's intimate relationships: a European study. Journal of Interpersonal Violence 2016; pii: 0886260516633204.

7. Klettke B, Hallford DJ, Mellor DJ. Sexting prevalence and correlates: a systematic literature review. Clinical Psychology Review 2014; 34:44-53.

8. Ringrose J, Gill R, Livingstone S, et al. (2012) Qualitative study of children, young people and "sexting." NSPCC. https://nspcc.org.uk/globalassets/documents/research-reports/ qualitative-study-children-young-people-sexting-report.pdf (accessed Apr. 25, 2017).

9. Livingstone S, Mascheroni G, Ólafsson K, et al. (2014) Children's online risks and opportunities: comparative findings from EU kids online and net children go mobile. London, United Kingdom: EU Kids Online, LSE.

10. Spacey R, Cooke L, Muir A, et al. Regulating use of the internet in public libraries: a review. Journal of Documentation 2014; 70:478-497.

11. Akdeniz Y. (2016) Internet child pornography and the law: national and international responses. New York, NY: Routledge.

12. Kelly S, Truong M, Shahbaz A, et al. (2016) Silencing the messenger: communication apps under pressure. https://freed omhouse.org/sites/default/files/FOTN_2016_BOOKLET_ FINAL.pdf (accessed May 1, 2017).

13. GSMA Europe. (2014) National measures. GSMA Europe. https://gsma.com/gsmaeurope/wp-content/uploads/2012/04/ Fourth_Implementation_Review_of_the_European-Frame work_for_Safer-Mobile-Use-by-Younger-Teenagers-andChildren.pdf (accessed Oct. 20, 2017).

14. Richmond S. (2012) Can parents control the websites their children look at? www.telegraph.co.uk/technology/internet/ 9223507/Can-parents-control-the-websites-their-childrenlook-at.html (accessed Jul. 7, 2016).
15. Deibert R, Palfrey J, Rohozinski R, et al. (2008) Access denied: the practice and policy of global internet filtering. Cambridge, MA: MIT Press.

16. United Nations Assembly. (1999) Convention on the rights of the child. Vol 1577. New York, NY: United Nations Children's Fund.

17. Mitchell KJ, Ybarra ML, Korchmaros JD, et al. Accessing sexual health information online: use, motivations and consequences for youth with different sexual orientations. Health Education Research 2014; 29:147-157.

18. Magee JC, Bigelow L, DeHaan S, et al. Sexual health information seeking online: a mixed-methods study among lesbian, gay, bisexual, and transgender young people. Health Education and Behaviour 2012; 39:276-289.

19. Ybarra ML, Finkelhor D, Mitchell KJ, et al. Associations between blocking, monitoring, and filtering software on the home computer and youth-reported unwanted exposure to sexual material online. Child Abuse Neglect 2009; 33:857-869.

20. Wolak J, Mitchell K, Finkelhor D. Unwanted and wanted exposure to online pornography in a national sample of youth internet users. Pediatrics 2007; 119:247-257.

21. Przybylski AK, Nash V. Internet filtering technology and aversive online experiences in adolescents. Journal of Pediatrics 2017; 184:215-219.e1.

22. Laupacis A, Sackett DL, Roberts RS. An assessment of clinically useful measures of the consequences of treatment. New England Journal of Medicine 1988; 318:1728-1733.

23. Suissa $S$. The number needed to treat: 25 years of trials and tribulations in clinical research. Rambam Maimonides Medical Journal 2015; 6 [Epub ahead of print]; DOI: 10.5041/ RMMJ.10218

24. Cook RJ, Sackett DL. The number needed to treat: a clinically useful measure of treatment effect. British Medical Journal 1995; 310:452-454.

25. O'Neill B, Livingstone S, McLaughlin S. (2014) Final recommendations for policy, methodology and research-LSE research online. http://eprints.lse.ac.uk/39410/ (accessed Oct. 17, 2017).

26. Przybylski AK, Nash V. (2017) Study materials, data, and code for filtering effectiveness analyses. https://osf.io/sxbgh/ (accessed May 5, 2018).

27. Cohen J. (1988) Statistical power analysis for the behavioral sciences. 2nd ed. Hillsdale, NJ: Routledge.

28. Nuovo J, Melnikow J, Chang D. Reporting number needed to treat and absolute risk reduction in randomized controlled trials. Journal of the American Medical Association 2002; 287:2813-2814.

29. Przybylski AK, Nash V. (2018) Preregistration for filtering effectiveness study and analyses. https://osf.io/8f3xw/ (accessed May 5, 2018).

30. Munafò MR, Nosek BA, Bishop DVM, et al. A manifesto for reproducible science. Nature Human Behaviour 2017; 1:0021.

31. Digital economy act 2017, c. 30. (2017) http://legislation. gov.uk/ukpga/ (accessed Oct. 20, 2017).

Address correspondence to: Prof. Andrew K. Przybylski 1 St. Giles

Oxfordshire

Oxford OX1 3JS England

E-mail: andy.przybylski@oii.ox.ac.uk 